\title{
Cylinders with a steel-concrete-steel wall to resist external pressure
}

\author{
C. D. Goode ${ }^{a *}$ and T. Nash ${ }^{b}$ \\ ${ }^{a}$ Civil Engineering Department, Manchester University, UK, (Retired). \\ ${ }^{\mathrm{b}}$ CDR Group, Sheffield, S33 6RW, UK. \\ *corresponding author, e-mail address: cdgoode@mypostoffice.co.uk
}

\begin{abstract}
In the 1980's Manchester University carried out over 110 tests on cylinders with a composite wall (steel-concrete-steel) subjected to external pressure as already reported in the literature. This paper describes further tests on 9 cylinders with a composite wall and a dome end subjected to external pressure and reports the results and compares them with theory. The cylinders were $500 \mathrm{~mm}$ diameter and 1250 $\mathrm{mm}$ long and four of them had penetrations through the cylinder wall. These tests were carried out under contract for Tecnomare SpA of Italy and have not been previously reported because of confidentiality reasons. The agreement between test behaviour, failure load and the theory developed at Manchester University is good.

The philosophy for the design of such vessels for seabed structures is discussed and a 'depth margin' method proposed as it is a more realistic way of applying safety. Examples of designs for different depths are given and compared with the predicted failure pressure.
\end{abstract}

Keywords: Composite wall; Cylinders; Sub-sea; Design philosophy.

\section{Introduction}

In the 1980's Manchester University carried out over 110 tests on cylinders with a doubleskin wall (steel-filler-steel) which have been reported in the literature [1-5]. In most cases the filler material was concrete with cube strengths from 20 to $87 \mathrm{~N} / \mathrm{mm}^{2}$. Nine tests, carried out under contract for Tecnomare SpA, of Italy, are described in this paper; they have not previously been reported because of confidentiality reasons. These 9 tests were carried out to verify the structural behaviour, integrity and strength of vessels with a 'sandwich' wall at about $1 / 20$ the scale of vessels required for sub-sea oil production. A design philosophy for such subsea structures is discussed.

\section{The Tests}

The nine cylinders were tested in the University of Manchester Civil Engineering hyperbaric chamber which could accommodate vessels up to $570 \mathrm{~mm}$ diameter and $1250 \mathrm{~mm}$ long loaded to a maximum pressure of $21 \mathrm{~N} / \mathrm{mm}^{2}$ their dimensions and properties are shown in Fig. 1.

Measurement of the radial deformation of the inside surface was made using radial displacement transducers which could be swept round through $360^{\circ}$. Strain gauges were also used to measure the longitudinal and circumferential strains on the steel skins; it was reassuring to see that the deformation from the transducers and that calculated from the strain gauges was in agreement.

The test vessels were fabricated by sleeving the inner skin into the outer skin, with stud spacers to align them and maintain the required wall thickness; micro-concrete, with a maximum aggregate size of $3 \mathrm{~mm}$, was then poured into the anulus and vibrated to compact it. The concrete cube strength was measured with the average being $50.2 \mathrm{~N} / \mathrm{mm}^{2}$. 


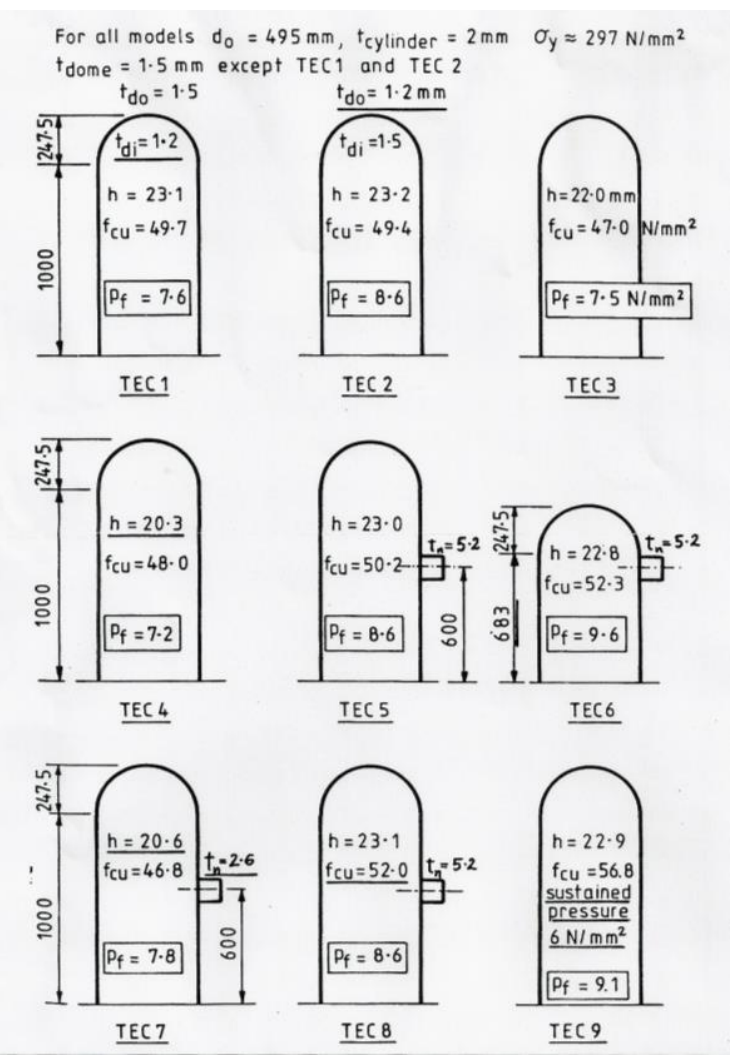

Fig. 1. Dimensions and properties of the shells

The test procedure was to increase the pressure in steps, measuring the internal deformation at each step by rotating the tube holding the transducers through $360^{\circ}$, in order to plot pressure against radial deformation of which Fig. 2 is typical. The plot is linear until the inside skin starts to yield when more load is placed on the concrete and outer skin until, after a small increase in pressure, this outer skin yields; after further increase in pressure the concrete crushes and an inward facing lobe is formed as seen in Figs. 3 and 4. By noting where the deformation was greatest it could be deduced where the failure lobe would form so the transducers were moved away from this zone to prevent them being damaged by the failure, the radial deformation was then deduced from the strain measurements; the pressure was then increased until failure occurred with a loud bang!

When failure occurs the pressure in the hyperbaric chamber reduces and stability is reached but it must be remembered that in a subsea situation this pressure would not reduce and collapse would be complete.

All the shells failed with the formation of an inward facing lobe by crushing of the concrete (as shown in Fig. 4) after yielding of the steel skins. The position of failure was in the cylinder

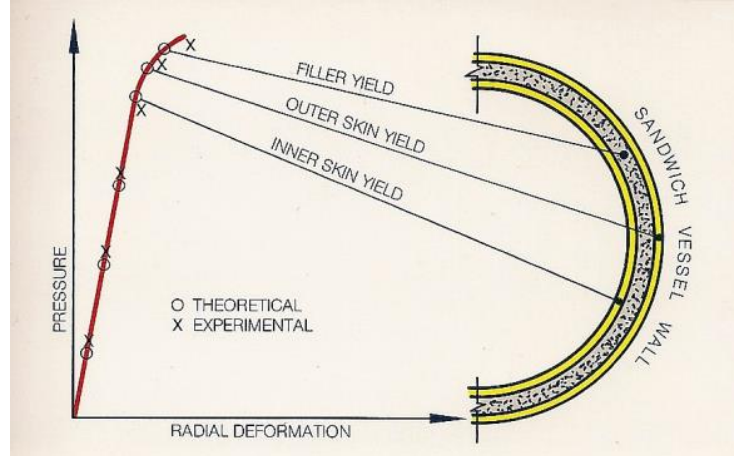

Fig. 2. Typical plot of pressure-deformation

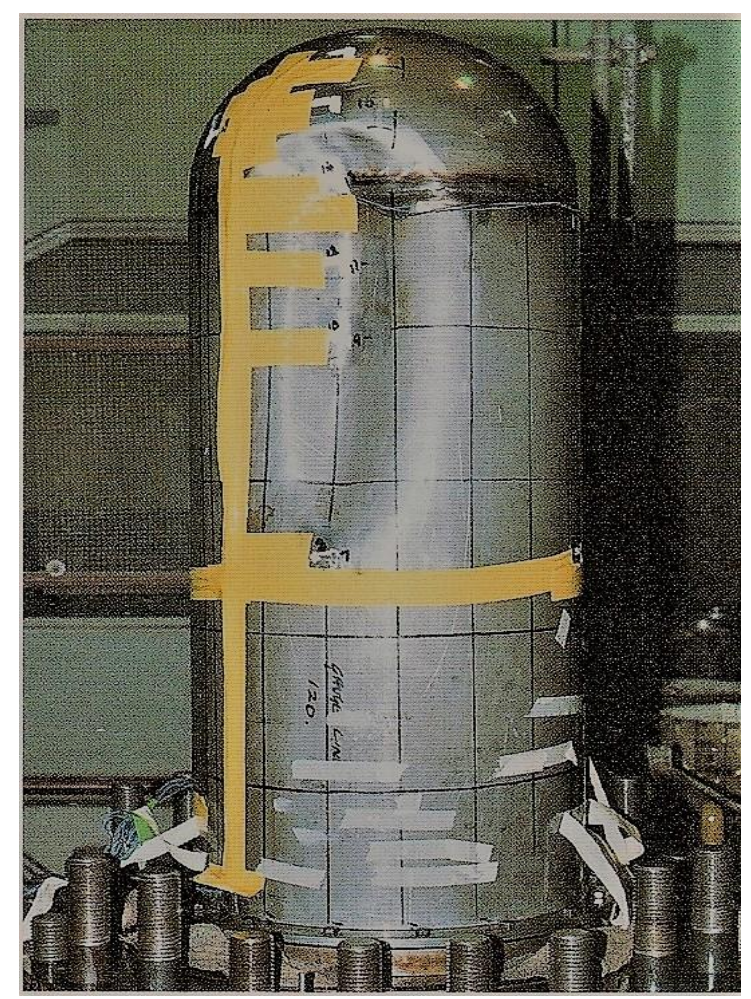

Fig. 3. Shell TEC1 after failure

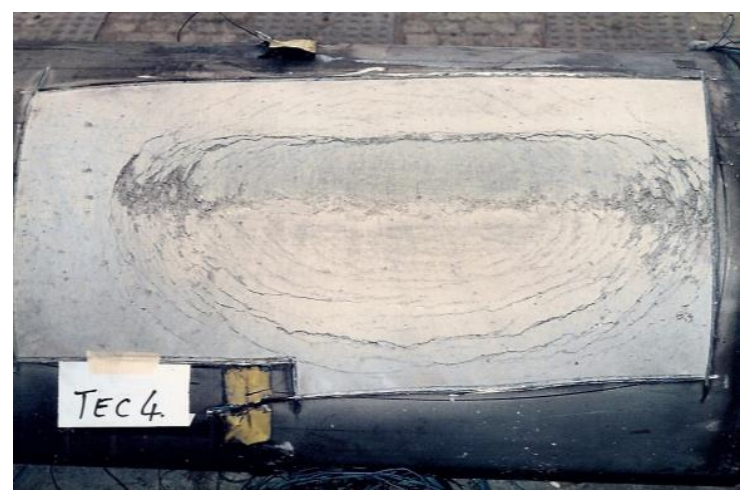

Fig. 4. Typical of the concrete failure surface after removal of outer the steel skin (Tec4)

length where the wall thickness (measured after the test) was thinnest, in some cases close to the 
junction between the cylinder and the dome as with TEC1 and TEC3. The steel skin thickness of all the cylinders was $2 \mathrm{~mm}$ and for the dome $1.5 \mathrm{~mm}$ except for TEC1 where the inner skin of the dome was $1.2 \mathrm{~mm}$ and TEC2 where the outer skin of the dome was $1.2 \mathrm{~mm}$. There was a penetration through the wall in TECs 4, 5, 6 \& 7 consisting of a steel tube welded to both inside and outside steel skins but in none of these four cases did the failure seem to be influenced by the penetration.

For shell TEC9 a sustained pressure of 6 $\mathrm{N} / \mathrm{mm}^{2}$, considered as the design working pressure for the shell, was maintained for a week before increasing it to failure to see if this affected the load at which the shell failed.

\section{Test results compared with theory}

There is good agreement between the test failure pressure $\left(\mathrm{p}_{\mathrm{fx}}\right)$ and the theoretical failure pressure $\left(p_{t}\right)[2,3]$, as shown in Table 1. The average $\mathrm{p}_{\mathrm{fx}} / \mathrm{p}_{\mathrm{t}}$ being 1.02; however TEC6 was shorter than the other cylinders so the failure lobe may not have had space to develop fully so, excluding TEC6, the average is 1.00. There is also good agreement between the theoretical and actual pressure-radial deformation behaviour (Fig. 2).

Table 1. Test failure pressure compared with theory.

\begin{tabular}{|c|c|c|c|}
\hline Shell & $\begin{array}{c}\text { Test } \\
\mathbf{p}_{\text {fx }} \mathbf{N} / \mathbf{m m}^{2}\end{array}$ & $\begin{array}{c}\text { Theory } \\
\mathbf{p}_{\mathbf{t}} \mathbf{N} / \mathbf{m m}^{2}\end{array}$ & $\mathbf{p}_{\text {fx }} / \mathbf{p}_{\mathbf{t}}$ \\
\hline TEC1 & 7.6 & 8.28 & $\mathbf{0 . 9 2}$ \\
\hline TEC2 & 8.6 & 8.29 & $\mathbf{1 . 0 4}$ \\
\hline TEC3 & 7.5 & 7.95 & $\mathbf{0 . 9 5}$ \\
\hline TEC4 & 7.2 & 7.68 & $\mathbf{0 . 9 4}$ \\
\hline TEC5 & 8.6 & 8.29 & $\mathbf{1 . 0 4}$ \\
\hline TEC6 & 9.6 & 7.90 & $\mathbf{1 . 2 2}$ \\
\hline TEC7 & 7.8 & 7.68 & $\mathbf{1 . 0 2}$ \\
\hline TEC8 & 8.6 & 8.42 & $\mathbf{1 . 0 2}$ \\
\hline TEC9 & 9.1 & 8.65 & $\mathbf{1 . 0 5}$ \\
\hline
\end{tabular}

The penetrations through the cylinder wall did not influence the behaviour or failure load. Sustained pressure at $70 \%$ of the failure pressure did not influence the failure load. The use of a skin thickness of $1.5 \mathrm{~mm}$ for the dome ends, $3 / 4$ the thickness of steel used for the cylinder section, did not cause failure to occur in the dome; though the use of an inner steel skin thickness of $1.2 \mathrm{~mm}$ for the dome of TEC1 may have contributed to its lower failure pressure $\left(\mathrm{p}_{\mathrm{fx}} / \mathrm{p}_{\mathrm{t}}=0.92\right)$ as the lobe did spread into the dome (Fig. 3).

The conclusion drawn from these tests (and the previous tests carried out at Manchester University) is that the use of a cylinder with a steel-concrete-steel wall provides an excellent form of construction for resisting external pressure and that the theory predicts the behaviour and failure pressure very well. Hemispherical domes can be used to close the ends of the cylinder with the steel thickness in the dome being $3 / 4$ of the steel thickness used in the cylinder length. The effect of point loads and damage to the composite wall has also been investigated $[4,5]$.

\section{Design philosophy for sub-sea vessels}

This form of construction has been applied by Tecnomare [6] to sub-sea production systems for oil extraction and they have produced designs for $1000 \mathrm{~m}$ water depth. Sir Robert McAlpine Ltd, as part of Deep Sea Production Systems, have also done designs for sub-sea vessels [7]; tests for them included five with an internal diameter of $1.3 \mathrm{~m}$, equivalent to $1 / 10$ scale [2], with this increase of scale the test failure pressure was the same as that predicted by the theory (for the 5 tests: average $\left.\mathrm{p}_{\mathrm{fx}} / \mathrm{p}_{\mathrm{t}}=1.00\right)$. With the higher strengths of material now available greater depths could be achieved.

Limit state design is acknowledged in Europe as being the most suitable method of ensuring that all stages of loading are considered and that the risk of exceeding each limiting criterion is acceptable. The human cost (injury and loss of life) and economic cost of repairing damage caused by any particular limit state being exceeded must not be disproportionate to the cause. If load intensities, their frequency of occurrence, and the variation of material properties could be defined precisely it would be possible to use statistical theory to arrive at the probability of reaching any particular criterion. This is rarely possible and designers resort to the deterministic approach of applying partial safety factors, to the loads and to the materials, the 
values of which are accepted by the majority of the industry. Their value is usually related to experience and they are accepted because they have proved satisfactory in past structures. In an innovative situation there is no prototype with which to compare; this is of course one of the principal reasons for model testing. Recommendations do exist in established codes (e.g. BS 5500 for the design of steel vessels subjected to external pressure). In the case of concrete the safety factors for sub-sea structures must be related to other usage and the current philosophy on safety. Composite construction has not been tested or used at the scale envisaged for a sea-bed vessel 9 to 12 metres in diameter. The partial safety factors applied to the loads and to the materials must therefore consider the values used for both steel and concrete construction. These values must then be justified by the results obtained from tests on models.

The consequences of failure are not explicitly mentioned but are usually assumed to be incorporated in the characteristic load and load factor used.

The principal load on a sea-bed structure is due to the water pressure. The design value of this will vary depending on the accuracy of the survey of the sea-bed at the chosen site, the height of the tides and waves and, to a lesser extent with currents. The authors propose that for such sea-bed structures it is much more appropriate to use a smaller partial load factor associated with a 'depth margin' as this will give a reliability against failure which is more consistent and less dependent on depth [8]. This approach will give safer structures at shallow depths and more economic structures at deeper depths. A load factor is still needed to take account the uncertainties in the assessment of the loading effects and a factor of 1.15 might be considered appropriate. The depth margin chosen would depend on the accuracy with which the vessel's position and sea-bed survey were known and would be added to the water depth including allowing for the greatest wave and tide height. The authors consider that $80 \mathrm{~m}$ is appropriate in many cases.

A comparison of designs for different depths is given in Table 2; all include material safety factors of 1.15 for steel and 1.5 for concrete. For instance allowing a depth margin of $80 \mathrm{~m}$ and a load factor of 1.15 and assuming a sea water

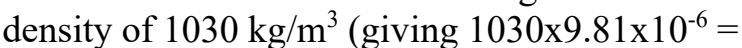

$0.0101 \mathrm{~N} / \mathrm{m}^{2}$ pressure per $\mathrm{m}$ depth) thus for $104 \mathrm{~m}$ depth (the design depth of the steel Frigg buoyancy tanks) the design pressure would be: $(104+80) \times 0.0101 \times 1.15=2.14 \mathrm{~N} / \mathrm{mm}^{2}$; and using only a load factor of 1.5 and no depth margin: $104 \times 0.0101 \times 1.5=1.58 \mathrm{~N} / \mathrm{mm}^{2}$.

Table 2. Comparison of design pressures using the 'Margin' and 'Load Factor' approaches.

\begin{tabular}{|c|c|c|}
\hline $\begin{array}{c}\text { Depth } \\
\mathrm{m}\end{array}$ & $\begin{array}{c}\text { Margin } 80 \mathrm{~m} \\
\mathrm{~N} / \mathrm{mm}^{2}\end{array}$ & $\begin{array}{c}\text { Load factor } 1.5 \\
\mathrm{~N} / \mathrm{mm}^{2}\end{array}$ \\
\hline 104 & $\mathbf{2 . 1 4}$ & $\mathbf{1 . 5 8}$ \\
\hline 263 & $\mathbf{3 . 9 8}$ & $\mathbf{3 . 9 8}$ \\
\hline 500 & $\mathbf{6 . 7 4}$ & $\mathbf{7 . 5 8}$ \\
\hline 1000 & $\mathbf{1 2 . 5 4}$ & $\mathbf{1 5 . 1 5}$ \\
\hline 2000 & $\mathbf{2 4 . 2}$ & $\mathbf{3 0 . 3}$ \\
\hline
\end{tabular}

Table 2 shows that the use of a depth margin gives more consistent safety and is a more realistic way of applying safety to structures subjected to external pressure loading caused by water depth than by applying only a load factor. Using a depth margin of $80 \mathrm{~m}$ gives greater safety at depths less than $263 \mathrm{~m}$ and is more economical at deeper depths.

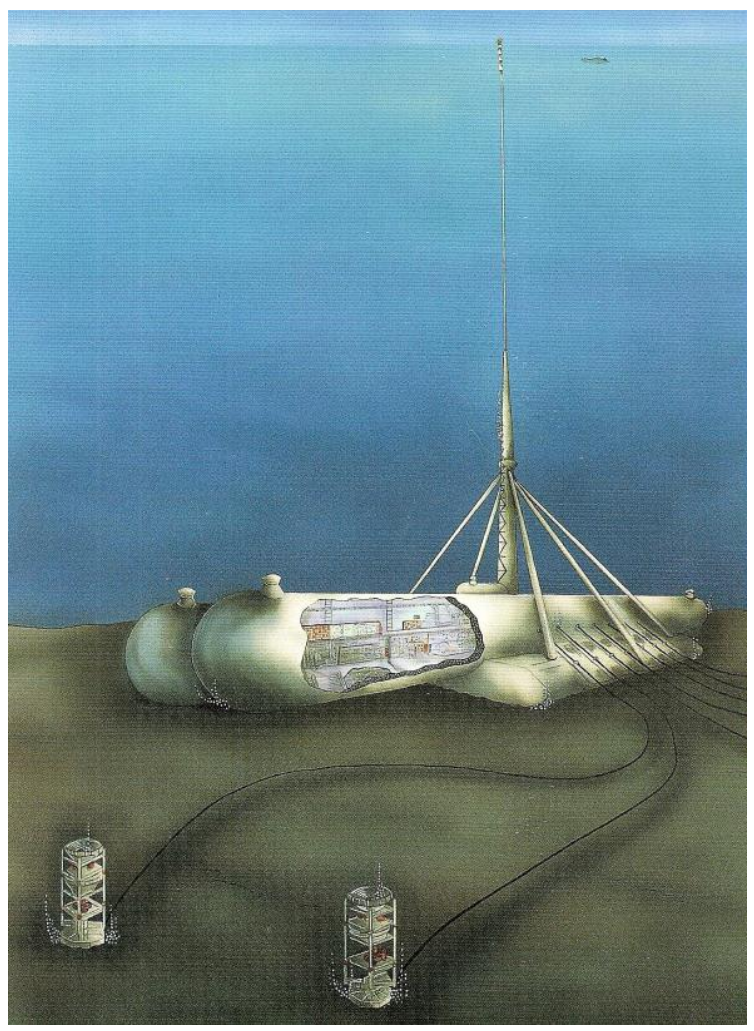

Fig. 5. Proposed Tecnomare Subsea Oil Production 


\section{Design comparisons}

Tecnomare's design, Fig. 5, for 1000 m water depth used a cylinder with a length of $170 \mathrm{~m}$ and an internal diameter of $12.5 \mathrm{~m}$ the wall thickness being $1 \mathrm{~m}$, their design had an internal steel skin thickness of $130 \mathrm{~mm}$ and an external steel skin thickness of $120 \mathrm{~mm}$ and they used commonly available materials, steel with a yield strength of $355 \mathrm{~N} / \mathrm{mm}^{2}$ and concrete with a cube strength of $65 \mathrm{~N} / \mathrm{mm}^{2}$. The design pressure for this $1000 \mathrm{~m}$ depth $\left(p_{\text {des }}\right)$ using a load factor of 1.5 would be $15.2 \mathrm{~N} / \mathrm{mm}^{2}$. The calculated failure pressure, when material partial safety factors of 1.15 for steel and 1.5 for concrete are included $\left(\mathrm{p}_{\mathrm{fd}}\right)$, would be $16.0 \mathrm{~N} / \mathrm{mm}^{2}$, equivalent to failing at a depth of $1583 \mathrm{~m}$, see Table 3 .

High strength steel and concrete could now be used to provide more economical sub-sea structures and be used for deeper depths; their use is shown in the last three rows of Table 3 for $1000 \mathrm{~m}$ and $2000 \mathrm{~m}$ depth designs.

Table 3 shows the savings in weight that can be achieved if the 'depth margin' approach to safety is adopted. The use of high strength materials also produces savings in weight, though there may be higher fabrication costs. For $2000 \mathrm{~m}$ depth the use of high strength materials gives a vessel of similar weight to that using standard materials for $1000 \mathrm{~m}$ depth (compare row 2 with row 6 in Table 3 ).

\section{Conclusions}

Cylinders with a composite wall, steelconcrete-steel, are a very efficient way of resisting external pressure. They have been extensively researched and tests show that their behaviour and failure can be accurately predicted by theory.

Although cylindrical vessels with composite walls have not, to our knowledge, been used in practice for sub-sea work they are an excellent form of construction for resisting external pressure. They have been considered for use in resisting blast loading and as containment vessels for nuclear waste, and they would also be useful for emergency shelters near volcanoes.

Design of sub-sea vessels should use a depth margin and small load factor rather than the normal ultimate limit state load factor alone.

Table 3. Examples of designs for dome ended cylinders with a steel-concrete-steel wall.

\begin{tabular}{|c|c|c|c|c|c|c|c|c|c|c|}
\hline Design & $\begin{array}{c}\mathbf{D}_{\mathbf{i}} \\
\mathbf{m m}\end{array}$ & $\begin{array}{c}\mathbf{h} \\
\mathbf{m m}\end{array}$ & $\begin{array}{c}\mathbf{t}_{\mathbf{i}} \\
\mathbf{m m}\end{array}$ & $\begin{array}{c}\mathbf{t}_{\mathbf{o}} \\
\mathbf{m m}\end{array}$ & $\begin{array}{c}\mathbf{f}_{\mathbf{y i}} \mathbf{f}_{\mathbf{y o}} \\
\mathbf{N} / \mathbf{m m}^{\mathbf{2}}\end{array}$ & $\begin{array}{c}\mathbf{f}_{\mathrm{cu}} \\
\mathbf{N} / \mathbf{m m}^{\mathbf{2}}\end{array}$ & $\begin{array}{c}\mathbf{p}_{\text {fd }} \\
\mathbf{N} / \mathbf{m m}^{\mathbf{2}}\end{array}$ & $\begin{array}{c}\mathbf{p}_{\text {des }} \\
\mathbf{N} / \mathbf{m m}^{2}\end{array}$ & $\begin{array}{c}\mathbf{W t}_{\mathbf{s t}} \\
\mathbf{1 0}^{\mathbf{3}} \mathbf{t}\end{array}$ & $\begin{array}{c}\mathbf{W t}_{\text {conc }} \\
\mathbf{1 0}^{\mathbf{3}} \mathbf{t}\end{array}$ \\
\hline Tec 1000m 1.5 & 12500 & 1000 & 130 & 120 & 355 & 65 & $\mathbf{1 6 . 0}$ & $\mathbf{1 5 . 2}$ & $\mathbf{1 5 . 1}$ & $\mathbf{1 4 . 1}$ \\
\hline Tec 1000m 80 & 12500 & 1000 & 90 & 80 & 355 & 65 & $\mathbf{1 2 . 5}$ & $\mathbf{1 2 . 5}$ & $\mathbf{1 0 . 2}$ & $\mathbf{1 5 . 6}$ \\
\hline McA 1000m 1.5 & 12000 & 1000 & 125 & 115 & 350 & 50 & $\mathbf{1 5 . 2}$ & $\mathbf{1 5 . 2}$ & $\mathbf{1 3 . 9}$ & $\mathbf{1 3 . 7}$ \\
\hline McA 1000m 80 & 12000 & 1000 & 100 & 80 & 350 & 50 & $\mathbf{1 2 . 5}$ & $\mathbf{1 2 . 5}$ & $\mathbf{1 0 . 4}$ & $\mathbf{1 4 . 8}$ \\
\hline HS 1000m 80 & 12000 & 600 & 60 & 40 & 650 & 80 & $\mathbf{1 2 . 9}$ & $\mathbf{1 2 . 5}$ & $\mathbf{5 . 6}$ & $\mathbf{8 . 7}$ \\
\hline HS 2000m 80 & 12000 & 1000 & 110 & 90 & 650 & 80 & $\mathbf{2 4 . 2}$ & $\mathbf{2 4 . 2}$ & $\mathbf{1 1 . 5}$ & $\mathbf{1 4 . 4}$ \\
\hline HS 2000m 1.5 & 12000 & 1400 & 130 & 115 & 650 & 80 & $\mathbf{3 0 . 6}$ & $\mathbf{3 0 . 3}$ & $\mathbf{1 4 . 6}$ & $\mathbf{2 1 . 5}$ \\
\hline
\end{tabular}

Notation used in Table 3: Tec are the Tecnomare designs, McA the McAlpine designs, and HS is the use of high strength steel and concrete; 1.5 indicates the use of a 1.5 load factor on the design depth to obtain the design ultimate limit state pressure $\mathbf{p}_{\text {des }} ; 80$ indicates the use of an $80 \mathrm{~m}$ depth margin and load factor of 1.15 to obtain the design ultimate limit state pressure pdes. The design failure pressure ( $\mathbf{p}_{\mathbf{f d}}$ ) predicted by the theory [2,3], includes material partial safety factors for steel $\left(\gamma_{\mathrm{ms}}=1.15\right)$ and for concrete $\left(\gamma_{\mathrm{mc}}=1.5\right)$; it should be compared to these $\mathbf{p}_{\mathrm{des}}$ values, and, for the vessel to be 'safe', $\mathbf{p}_{\mathbf{f d}}$ should be equal to or greater than $\mathbf{p}_{\text {des. }}$

$\mathbf{p}_{\mathrm{fd}}=2 *\left(\left(\mathrm{t}_{\mathrm{o}} * \mathrm{f}_{\mathrm{yo}} /\left(\gamma_{\mathrm{ms}}+\mathrm{t}_{\mathrm{i}} * \mathrm{f}_{\mathrm{yi}} /\left(\gamma_{\mathrm{ms}}\right)+\left(\mathrm{h}-\mathrm{t}_{\mathrm{i}}-\mathrm{t}_{\mathrm{o}}\right) *\left(0.75 * \mathrm{f}_{\mathrm{cu}} /\left(\gamma_{\mathrm{mc}}+\left(6 * \mathrm{t}_{\mathrm{i}} * \mathrm{f}_{\mathrm{yi}} /\left(\gamma_{\mathrm{ms}}\right)\left(\mathrm{D}_{\mathrm{i}}+2 * \mathrm{t}_{\mathrm{i}}\right)\right)\right) /\left(\mathrm{D}_{\mathrm{i}}+2 * \mathrm{~h}\right)\right.\right.\right.\right.$ see $[2,3]$ $\mathrm{D}_{\mathrm{i}}=$ internal diameter of the cylinder; $\mathrm{h}=$ the total wall thickness; $\mathrm{t}_{\mathrm{i}}, \mathrm{t}_{\mathrm{o}}=$ the thickness of the inside and outside steel skins respectively, and $\mathrm{f}_{\mathrm{yi}} \& \mathrm{f}_{\mathrm{yo}}$ their yield strengths; $\mathrm{f}_{\mathrm{cu}}=$ the characteristic cube strength of the concrete. $\mathrm{Wt}_{\mathrm{st}}$ and $\mathrm{Wt}_{\text {conc }}$ are the weight, in thousands of tonnes $(1000,000 \mathrm{~kg})$, of the steel and concrete respectively for a $170 \mathrm{~m}$ long cylinder with domed ends (the steel in the dome ends being $3 / 4$ of the thickness of the steel used in the cylinder length).

\section{Acknowledgements}

Tecnomare SpA of Italy is thanked for providing the financial support for this work.
The tests were carried out at Manchester University by Dr. Tom Nash, John Smith \& Alan Graham under the direction of the late Professor Peter Montague. 


\section{References}

[1] Goode CD \& Fatheldin YT. Sandwich cylinders (steel-concrete-steel) subjected to external pressure. ACI Journal 1980; 77(2): 109-115.

[2] Montague P, Nash T, Goode CD, Large steel-concrete composite cylinders under external pressure. Proc. ICE Structures and Buildings 1996; 116(2): 174-185.

[3] Nash T \& Montague P. The strengthstability interaction of doublé-skin, composite circular shells under external pressure. Proc. Mech Eng 1989; 189C(16): 293-301.

[4] Shukry MES \& Goode CD. Punching shear strength of composite construction. ACI Structural Journal 1990; 87(1): 12-22.
[5] Goode CD \& Shukry MES. The effect of damage to composite cylinders subjected to external pressure. ACI Structural Journal 1988; 85(4): 405-413.

[6] Tecnomare SpA. The Tecnomare Subsea Production System, Venice 1997; Tecnomare SpA, San Marco 3584, 30124 Venice.

[7] Montague P \& Collard MS. The deep Sea Production System. Proc. Eng. Section, British Association for the Advancement of Science Liverpool 1982; CIRS UK: 25-47.

[8] Goode CD. Design philosophy for composite construction. Integrity of Offshore Structures-4 Glasgow 1990; Elsevier Applied Science, London 1990: 231-245. 